DOI: https://doi.org/10.17308/geology.2020.1/2511

Поступила в редакцию: 14.02 .2020

Принята к публикации: 20.02.2020

Опубликована онлайн: 25.03 .2020

\title{
Разломы в фундаменте восточной части Воронежского кристаллического массива по морфометрическим данным
}

\author{
А. И. Трегуб ${ }^{1 \bowtie}$, Д. Е. Шевцов ${ }^{2}$ \\ ${ }^{1}$ Воронежский государственный университет, \\ Университетская пл., 1, 394018, Воронеж, Российская Федерация \\ ${ }^{2}$ Институт геотехники и инженерных изысканий в строительстве, \\ ул. Средне-Московская, 92, 394006, Воронеж, Российская Федерация
}

\begin{abstract}
Аннотация
Введение: Разломы в фундаменте Воронежского кристаллического массива (ВКМ) играют важную роль, как в формировании структуры осадочного чехла, так и в особенностях минерагении территории. Их современная активность влияет на сейсмичность региона, а также на развитие экзогенных геологических процессов. Картирование разломов требует комплексного подхода, включающего геоморфологические методы. Однако применение этих методов должно иметь ряд ограничений.

Методика: На основе цифровой модели рельефа восточной части Воронежского кристаллического массива выполнен статистической анализ высот земной поверхности. Он включал определение и интерпретацию центральных моментов распределения высот.

Результаты и обсуждение: Зоны разломов в кристаллическом фундаменте восточной части Воронежского кристаллического массива находят избирательное отражение в морфометрических параметрах рельефа земной поверхности. Выделяются современные активные разломные зоны, зоны активные на неотектоническом этапе, а также зоны разломов, которые пассивно проявляются в цифровой модели рельефа. Надвиги и шарьяжи, которые сформировались на заключительных этапах консолидации фундамента, не находят своего полного отражения в морфометрических показателях современного рельефа.

Заключение: Результаты исследований могут быть использованы при геологическом картировании, инженерно-геологических изысканиях, эколого-геологических исследованиях и в сейсмическом районировании территории.

Ключевые слова: зоны разломов, кристаллический фундамент, Воронежский кристаллический массив, морфометрические параметры рельефа, неотектоника, морфоструктура, цифровая модель рельефа.
\end{abstract}

Для изитирования: Трегуб А. И., Шевцов Д. Е. Разломы в фундаменте восточной части Воронежского кристаллического массива по морфометрическим данным // Вестник Воронежского государственного университета. Серия: Геология. 2020. №1. C. 30-38. DOI: https://doi.org/10.17308/geology. 2020.1/2511

\section{Введение}

Разломы в фундаменте Воронежского кристаллического массива (ВКМ) играют важную роль, как в формировании структуры осадочного чехла, так и в особенностях минерагении территории $[1,2]$. Их современная активность в значительной степени влияет на специфику сейсмичности региона [3],

Контент доступен под лицензией Creative Commons Attribution 4.0 License.

\footnotetext{
$凶$ Трегуб Александр Иванович, E-mail: tregubai@yandex.ru
} 
а также на развитие современных экзогенных геологических процессов.

Представленные различными авторами варианты блоковой структуры фундамента ВКМ при общем сходстве характеризуются существенными отличиями в деталях $[1,4]$. Это требует поиска дополнительной информации, позволяющей более точно устанавливать пространственное положение разломных зон. При изучении блокового строения фундамента, наряду с геолого-геофизическими материалами, предлагается использовать информацию по неотектонике и, в частности, морфоструктурные методы изучения разрывных нарушений [5]. Применение этих методов, однако, требует учета их особенностей и ограничений, которые связаны с тем, что формирование морфометрических характеристик рельефа земной поверхности происходит под влиянием, прежде всего, вертикальных тектонических движений. Поэтому отражение в неотектоническом рельефе могут найти активные разломы с вертикальным направлением смещения (сбросы, взбросы, взрезы), а также зоны разрывных нарушений сдвигового типа, в инфраструктуре которых проявлены пул-апартные элементы. При этом необходимо учитывать, что на отражение разломов фундамента в рельефе земной поверхности оказывает влияние осадочный чехол, в котором могут развиваться области динамического влияния разломов. При пересечении с поверхностью Земли они проявляются зонами динамического влияния [6]. На инфраструктуру зон динамического влияния оказывает существенное влияние трещиноватость пород осадочного чехла [7]. Она часто образует линейные полосы повышенной проницаемости с приуроченными к ним денудационными процессами и формами экзогенного рельефа. Эти полосы могут выступать в качестве отражения как активных, так и «пассивных» разломных зон фундамента, не проявленных в новейшей структуре, но испытавших активизацию на различных этапах формирования чехла. Ширина полос связана со стадиями развития области динамического влияния. Максимальным значением ширина обладает на ранней (пликативной) стадии развития, при которой реализуются пластические деформации пород чехла. По мере развития деформационного процесса ширина полосы сокращается, в инфраструктуре зоны влияния появляются изолированные деструктивные поля, образованные концентрацией мелких разрывных нарушений. На заключительной стадии в осадочном чехле за счет порангового слияния разрывов деструктивных полей возникает магистральный шов, отражающий общее положение сместителя. Ширина полосы достигает минимальной величины [6]. Важную информацию о состоянии разломных зон можно получить при использовании морфоструктурных методов, основанных на цифровых и стохастических моделях рельефа [5]. Они позволяют оценить, как общие тенденции в активности разломных зон, так и уточнить их пространственное положение, зависимость от современных и неотектонических движений.

\section{Методика}

Для морфометрического анализа использованы цифровые модели рельефа (ЦМР), а также средства и методы их обработки на основе геоинформационных технологий. В качестве такой модели применена высотная матрица SRTM, полученная с применением радиолокаторов космического корабля Shuttle (Discovery) [7]. Эти данные доступны в виде отдельных матриц 5 на $5^{\circ}$ по 6001 ячеек с пространственным разрешением около 80 м и вертикальным разрешением 1 м. В работе использован единый набор радарных данных четвертого уровня подготовки в диапазоне $39^{\circ}-43^{\circ}$ по долготе и $49.3^{\circ}-53.3^{\circ}$ по широте, составленный из четырех исходных матриц. Размер обрабатываемой матрицы - 3501 на 5551 ячеек или примерно 280 на 444 км.

Предварительно матрица SRTM была обработана при помощи модуля гидрологического моделирования Spatial Analyst ArcGIS для ликвидации локальных замкнутых понижений (функция Fill). Необходимость ее использования определяется наличием ошибок в исходных данных SRTM в виде небольших изолированных аномалий, связанных с ошибочными флуктуациями принимаемого сигнала. Отрицательные аномалии чаще всего появляются на пойменных участках речных долин и могут иметь абсолютные значения намного ниже уреза воды. В процессе выполнения данной функции локальные понижения были отфильтрованы и сглажены, в соответствии с окружающим их рельефом, в результате чего была получена естественная поверхностно-проточная ЦМР (рис. 1А). Для определения статистических характеристик рельефа в качестве элементарной ячейки для обработки данных выбрана сетка 4 на 4 км. Был создан, согласный с ней, полигональный слой объектов квадратной формы и слой точек, соответствующий центроидам данных квадратов. Один квадрат соответствовал 2500 (50х50) ячеек SRTM. На основе пространственных выборок для каждого квадрата получены значения SRTM, которые были приведены к табличному виду с переносом в атрибуты высотных значений рельефа. Обработка данных табличных выборок осуществлена в пакете анализа Excel c получением описательной статистики по каждой из них, поскольку некоторые из моментов распределения высоты рельефа (асимметрия, эксцесс) невозможно получить прямыми расчетами в скользящем окне при помощи модуля Spatial Analyst ArcGIS. Pacсчитаны следующие моменты распределения высоты земной поверхности: математическое ожидание, дисперсия и стандартное отклонение, а также коэффициент асимметрии. Статистические показатели были присоединены в качестве атрибутов к точкам-центроидам квадратов 4 на 4 км и интерполированы методом Spline с получением соответствующих статистических полей и последующим построением картографических моделей по основным параметрам распределений. Опытным путем было установлено, что статистические поля для визуализации оптимально классифицируются $1 / 2$ в долях стандартных отклонений. 

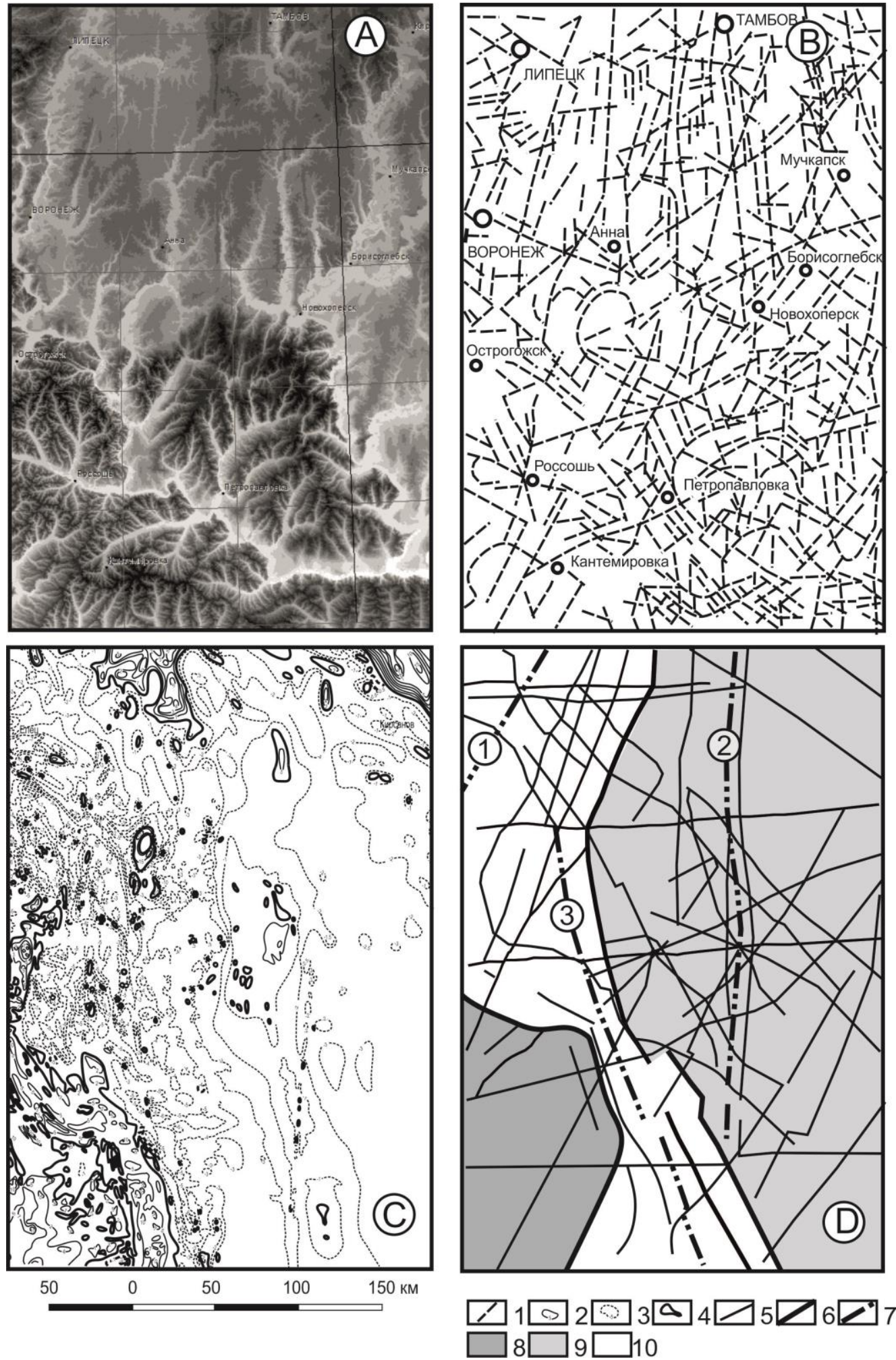

Рис. 1. Соотношение цифровой модели рельефа с блоковой структурой фундамента: $A$ - цифровая модель рельефа [7]. $B-$ схема структурных линий: 1 - структурные линии. $C$ - карта аномалий магнитного поля [1]: 2 - изолинии положительных аномалий, 3 - изолинии отрицательных аномалий, 4 -нулевые изолинии. $D$ - схема мегаблоков фундамента [4]: 5 - разломы, 6 - разломы на границах мегаблоков, 7 - наиболее крупные разломные зоны (цифры в кружках): 1 - Ряжско-Кантемировская, 2 - ШумилинскоНовохоперская, 3 - Лосевско-Мамонская. Мегаблоки: 8 - КМА, 9 - Хоперский, 10 - Лосевская шовная зона.

[Fig. 1. Correlation of the digital terrain model with the block structure of Foundation: $A$ - digital terrain model [7]. $B-$ scheme of structural lines: 1 - structural lines; $C$ - map of magnetic field anomalies [1]: 2 - isolines of positive anomalies, 3 - isolines of negative anomalies, 4 - zero isolines. $D$ - scheme of megadlocks of Foundation: 5 - faults, 6 - faults at the boundaries of megablocks, 7 - is the largest fault zone (numbers in circles): 1 - Ryazhsko - Kantemirovskaya, 2 - Shumilinsko - Novokhoperskaya, 3 - Losevsko - Mamonskaya. Megablocks: 8 - KMA, 9 - Khoperskiy, 10 - Losevskaya suture zone]. 
При интерпретации статистических параметров математическое ожидание рассматривалось в качестве средней высоты поверхности, дисперсия и стандарт характеризовали уровень вертикального расчленения (энергию рельефа). С позиций морфометрического анализа карты средних высот земной поверхности характеризуют морфологические особенности неотектонической составляющей в рельефе [5]. Карта дисперсий (стандартов), отражая запасы потенциальной энергии в рельефе, является аналогом карт остаточного рельефа. Она позволяет отделить в морфоструктуре неотектоническую составляющую от литоморфной. Литоморфная компонента, тесно связанная с устойчивостью пород против денудации, позволяет проявить в рельефе зоны повышенной проницаемости в породах разного возраста [5]. Принципиально новую информацию по сравнению с традиционной морфометрией позволяют получить карты коэффициентов асимметрии распределения высот. Отражая соотношения средних высот с высотами меньшими и большими, чем средние, коэффициенты асимметрии характеризуют современное положение территории в геоморфологическом цикле. Области с отрицательными значениями коэффициента рассматриваются как области с нарастающим расчленением рельефа. Они отмечают территории, испытывающие современные поднятия. Положительные значения коэффициента соответствуют областям, испытывающим выравнивание рельефа. Они могут быть интерпретированы как участки относительных погружений.

\section{Результаты и обсуждение}

Восточная часть Воронежского кристаллического массива в тектоническом отношении интересна тем, что охватывает область сочленения трех крупных и разнородных структурных элементов - мегаблока КМА, Хоперского мегаблока и Лосевской шовной зоны между ними $[1,4]$.

Мегаблоки и составляющие их более мелкие блоки разделены разломами. Разломы в фундаменте образуют несколько возрастных генераций, сформированных в различных геодинамических обстановках [5]. Они имеют длительную историю развития, в продолжение которой при многократных изменениях параметров поля тектонических напряжений изменяли свою кинематику и активность. В целом, для структуры фундамента в геодинамической интерпретации на конец раннего протерозоя преобладали шарьяжи и разломы надвигового типа, сопряженные со сдвигами, образовавшимися в условиях горизонтального сжатия [1]. На авлакогенной стадии, при смене горизонтального сжатия на растяжение на границах рифтогенных структур сформировались нарушения со сбросовой кинематикой. На плитной стадии развития разломы в фундаменте служили структурным каркасом, который во многом определял формирование штамповых структур осадочного чехла [5]. Среди наиболее крупных долго живущих зон характеризуемой территории выделяются: Ло-
севско-Мамонская, Ряжско-Кантемировская, Шумилинско-Новохоперская (рис. 1D). В девоне с этими зонами связан базальтовый магматизм [2].

По результатам анализа цифровой модели рельефа (ЦМР) выделяется большое количество структурных линий, под которыми, вслед за Г. И. Раскатовым [8], подразумевается возможное проявление пликативных и разрывных нарушений фундамента и чехла через особенности строения рельефа земной поверхности.

Использование этого понятия вместо термина «линеамент», имеющего сходное значение, может быть оправдано тем, что линеаменты выделяются на дистанционных материалах не только по рельефу, но и по множеству других дешифровочных признаков: фототону изображения, характеру растительного покрова, гидрогеологическим характеристикам и т. п. Среди структурных линий наиболее отчетливо проявлены несколько протяженных зон (рис. 1В). Зона северо-западного простирания шириной 25-30 км, лишь фрагментарно совмещающаяся с Лосевско-Мамонской разломной зоной, которой в аномальном магнитном поле соответствует полоса смены характера магнитного поля. Полоса структурных линий меридионального направления шириной 20-25 км отчетливо совмещается с Шумилинско-Новохоперским разломом. Разлом в магнитном поле фиксируется, особенно в южной половине территории, цепочкой мелких изометричных аномалий, приуроченных к выходам базальтов (рис. 1С).

Фрагмент Ряжско-Кантемировской разломной зоны северо-восточного простирания выражен слабее, как в ЦМР, так и в магнитном поле. Многие разломы широтного простирания, изображенные на тектонических схемах, в структурных линиях на ЦМР, практически не находят полного своего отражения, равно как и в магнитном поле. И, наоборот, достаточно многие протяженные полосы структурных линий не фиксируются на тектонических схемах фундамента.

В цифровой модели рельефа и на карте дисперсии высот восточной части ВКМ отчетливо выражены наиболее крупные неотектонические элементы: западная часть Окско-Донской депрессии, восточное крыло Среднерусского поднятия, а также Калачское поднятие. Границы наиболее крупных неотектонических структур проявлены резкими перепадами уровня вертикального расчленения земной поверхности. Непосредственно между Среднерусским поднятием и Окско-Донской впадиной расположен линейный Кривоборский неотектонический прогиб [9], а Калачское поднятие с юго-запада ограничено ПавловскоМамонским неотектоническим прогибом. По анализу карты энергии рельефа количество выделяемых структурных линий существенно меньше, чем на схеме ЦМР (рис. 2). Это, вероятно, объясняется избирательным отражением разломов. В энергии рельефа структурными линиями проявлены только нарушения активные на неотектоническом этапе. Часть из них совмещаются с разломами в фундаменте, выделенными по геолого-геофизическим данным [1]. 

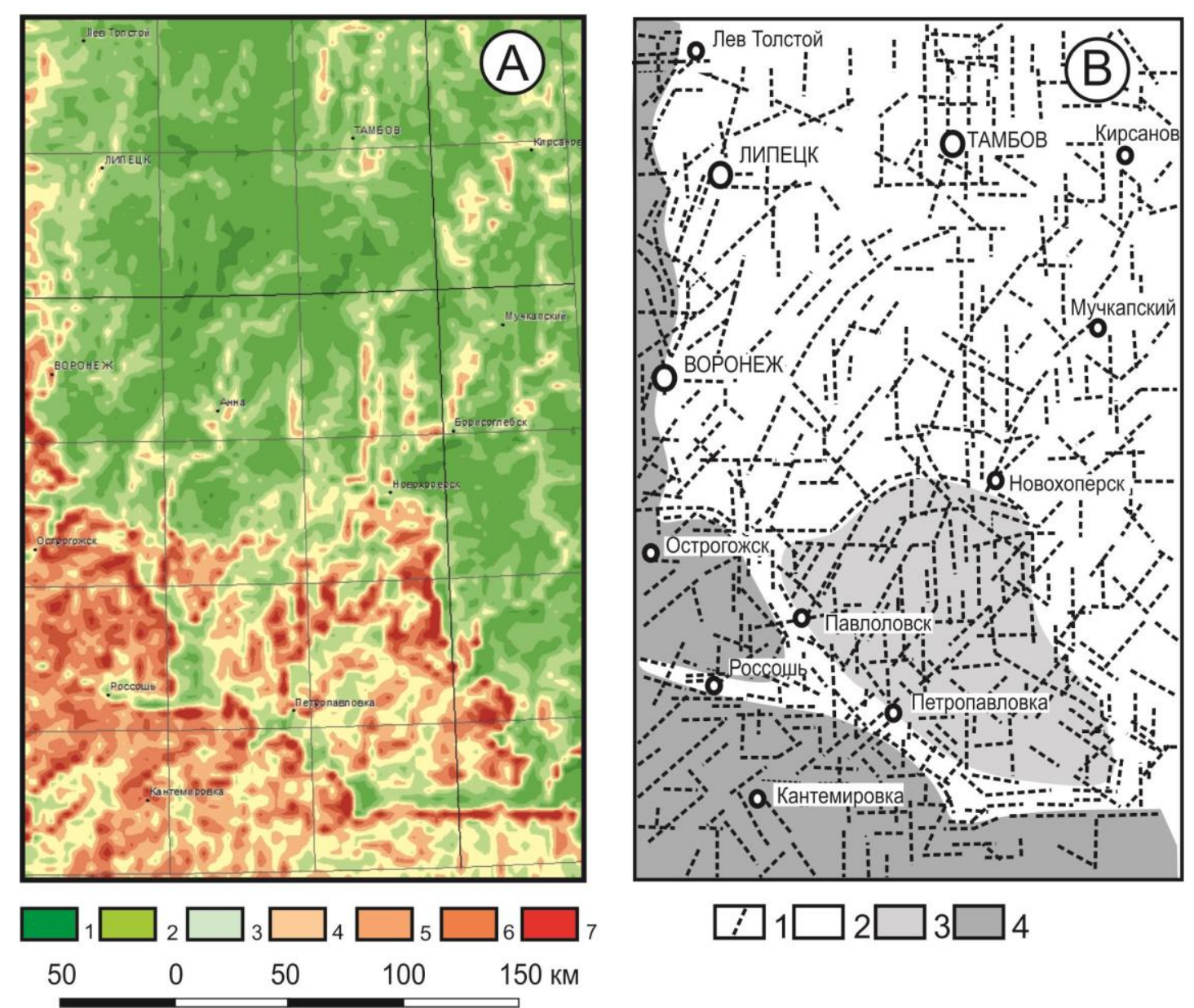

Рис. 2. А - карта дисперсии высот земной поверхности (энергии рельефа): 1-7- уровень расчленения (м/км²) от 10 до $70 . B-$ схема структурных линий, выделенных по анализу энергии рельефа: 1 - структурные линии. Элементы неотектоники [9]: 2 - Окско-Донская депрессия; 3 - Калачское поднятие; 4 - Среднерусское поднятие.

[Fig. 2. A - map of the dispersion of the earth's surface heights (terrain energy): 1-7 - the level of dissection ( $\left.\mathrm{m} / \mathrm{km}^{2}\right)$ from 10 to $70 . B$ - scheme of the structural lines selected from the analysis of terrain energy: 1 - structural lines. Elements of neotectonics [9]: 2 - OkskoDonskaya depression, 3 - Kalachskoye uplift, 4 - Srednerusskoye uplift].

Наиболее отчетливо такое совмещение наблюдается для зоны Шумилинско-Новохоперского разлома. Ширина полосы структурных линий здесь местами достигает 30 км. Это позволяет предположить наличие нескольких параллельных разломных зон в фундаменте, активизированных на неотектоническом этапе. Зона Шумилинско-Новохоперского разлома в новейшей структуре территории характеризуется сложной кинематикой, меняющейся на различных по простиранию ее участках [10].

Часть Ряжско-Кантемировской разломной зоны, расположенная в пределах характеризуемой территории выражена фрагментарно у г. Липецка и к северовостоку от него узкой полосой структурных линий северо-восточного простирания. Отдельные участки зоны Лосевско-Мамонского разлома в новейшей структуре совмещаются с линейным ПавловскоМамонским прогибом и его широтным продолжением на южном ограничении Калачского поднятия. Признаки сдвиговой кинематики для этой разломной зоны предполагаются по анализу строения поймы и параметров голоценового аллювия Дона [11].
На карте коэффициентов асимметрии распределения высот земной поверхности (рис. $3 \mathrm{~A}$ ) существенно снижается степень контрастности границ основных элементов новейшей тектонической структуры. Обращают на себя внимание выделяющиеся области с преобладанием различных по знаку коэффициентами. Они отражают положение рельефа в геоморфологическом цикле и через него состояние современных вертикальных тектонических движений. В соответствии с этим области современных поднятий расположены в восточной части Окско-Донской депрессии, а также на северо-западе территории в пределах Среднерусского поднятия. Условия слабых относительных погружений сосредоточены на северо-западе ОкскоДонской впадины, в южной части Калачского поднятия и на юго-востоке Среднерусского поднятия. Структурные линии, выделяемые в пределах Калачского и Среднерусского поднятий, проявляются фрагментарно, а в области Окско-Донской депрессии, напротив, они выражены более резко. Вместе с тем, проявляются новые их направления, которые были затушеваны на схемах, составленных по карте энергии 

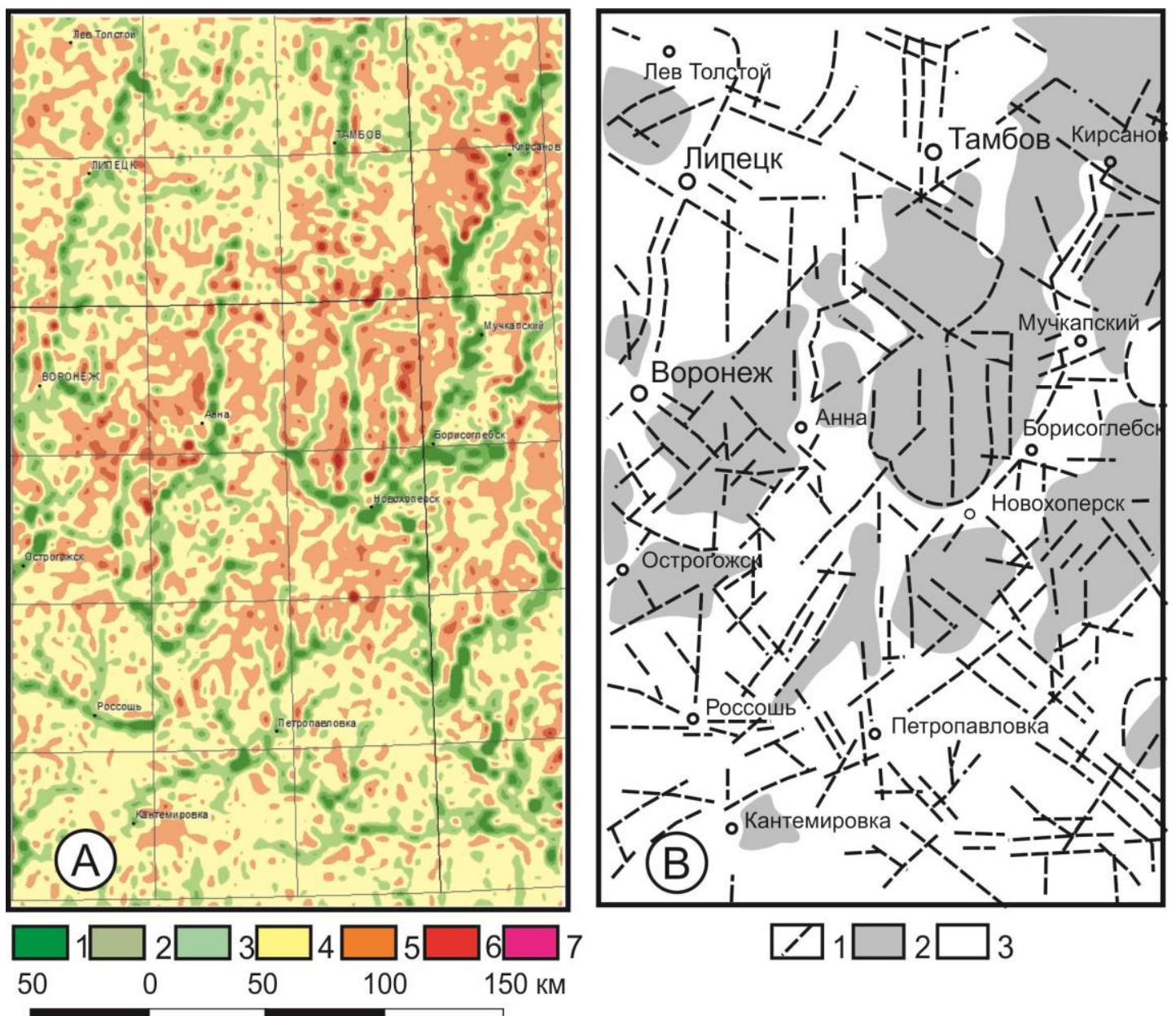

Рис. 3. А - карта коэффициентов асимметрии распределения высот. Величина коэффициента (от - до): $1--0.4--2.3 ; 2--2.3-$ $-1.5 ; 3--1.5--0.6 ; 4--0.2-+0.2 ; 5-+0.2-+1.5 ; 6-+1.5+1.9 ; 7->+1.9$. В - Схема структурных линий: $1-$ структурные линии; 2 - области с преобладающим выравниванием рельефа; 3 - области с преобладающим расчленением рельефа.

[Fig. 3. A - the map of the skewness of the distribution of heights. The value of the coefficient (from -to): $1--0.4--2.3 ; 2--2.3-$ $1.5 ; 3--1.5--0.6 ; 4--0.2-+0.2 ; 5-+0.2-+1.5 ; 6-+1.5+1.9 ; 7->+1.9$. B - scheme of the structural lines; $1-$ structural lines; $2-$ areas with the predominant alighment of the relief; 3 - areas with the predominant compartmentalization of the relief.]

рельефа и ЦМР. Современная активность разломных зон, выделяющихся по структурным линиям карты коэффициентов асимметрии, подтверждается и расположением эпицентров землетрясений [3].

Участки с наибольшей их плотностью расположены на пересечении структурных линий южнее Острогожска, в районе города Липецка и к северо-западу от него. Полосы эпицентров приурочены к участкам меридиональных структурных линий вдоль зоны Шумилинско-Новохоперского разлома, а также ПавловскоМамонского неотектонического прогиба. Их наибольшая концентрация наблюдается южнее Острогожска, где отмечается интенсивная раздробленность докембрийского фундамента (рис. 4В). Зона ШумилинскоНовохоперского разлома эпицентрами отмечена фрагментарно (на севере и юге). Многие разломы фундамента, выделенные при кинематической интерпретации в качестве надвигов и шарьяжей [1], не находят отражения в неотектонической структуре территории, а также на схеме современной активности разрывных нарушений (рис. 4А). Проявляются лишь отдельные их фрагменты, обладающие, повидимому, взбросовой кинематикой. Можно предположить, что новейшая и современная активизация разломных зон в фундаменте, а также степень их отражения в параметрах рельефа обусловлены особенностями поля новейших тектонических напряжений территории Русской плиты. В нем преобладает горизонтальное сжатие, ориентированное в меридиональном направлении $[5,12]$.

\section{Заключение}

Таким образом, предлагаемая методика позволяет на основе анализа цифровой модели рельефа обозначить возможное положение разломов в фундаменте и областей их динамического влияния в осадочном чехле; используя статистические модели рельефа выделить зоны, активные на неотектоническом этапе (карты энергии рельефа), а также обладающие современной активностью (карты асимметрии распределения высот). Вместе с тем, выделение разломов в фундаменте и их наиболее полная характеристика может 

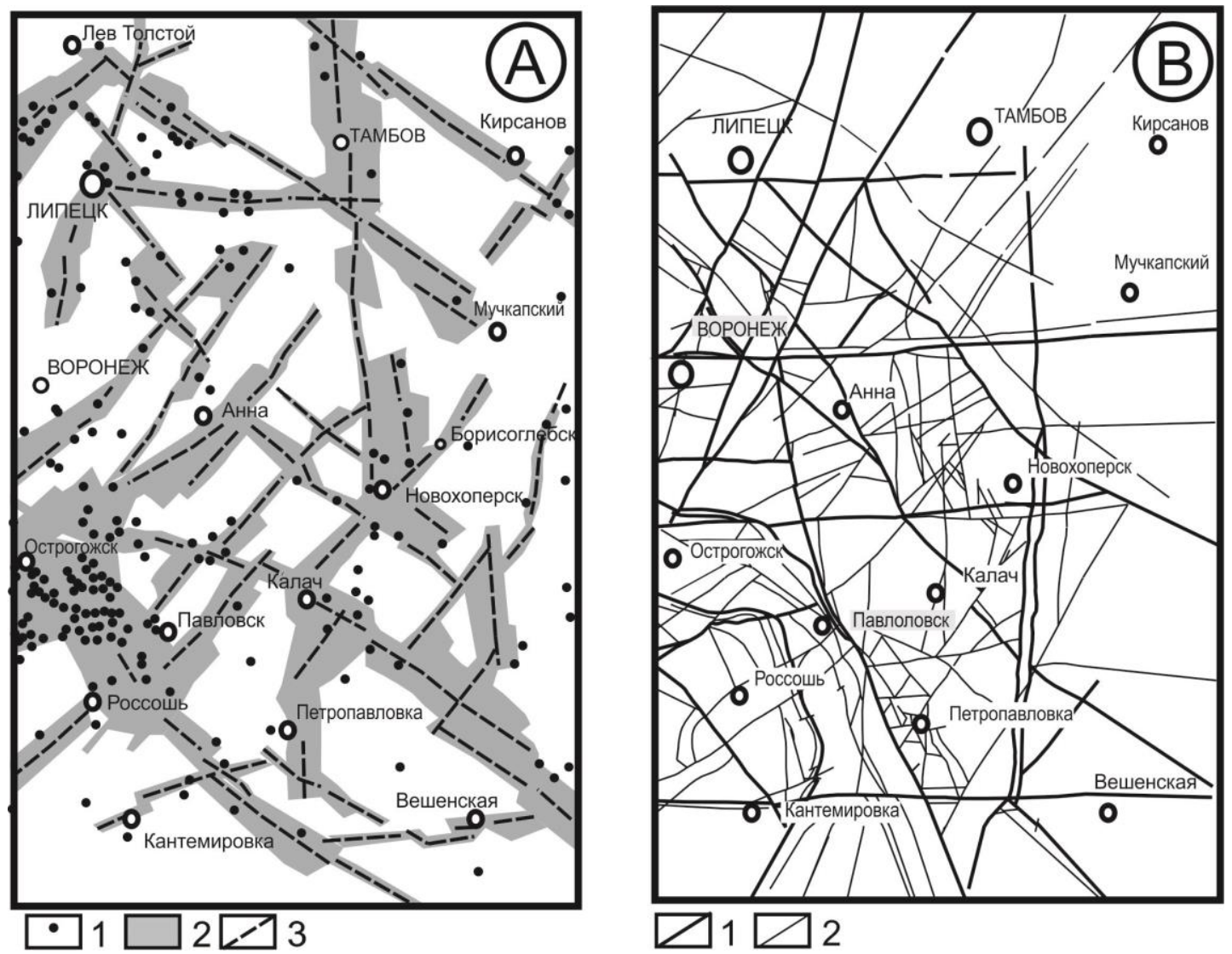

Рис. 4. Сопоставление современных активных разломных зон со схемой разломов в фундаменте: $A$ - современные активные разломные зоны. 1 - эпицентры землетрясений (по [3]); 2 - зоны динамического влияния разломов; 3 - магистральные линии. $B$ схема разломов в фундаменте (по [1]). 1 - разломы первого ранга; 2 - второстепенные разрывные нарушения.

[Fig. 4. Comparison of the modern active fault zones with the fault diagram in Foundation (by [1]): $A$ - modern active fault zones. $1-$ epicentres of earthquake (by [3]); 2 - zones of dynamic influence of faults; 3 - main lines. $B$ - scheme of faults in the Foundation (by [1]. 1 faults of the first rank; 2 - minor discontinuities.]

быть дана при комплексном подходе, включающем геолого-геофизические данные, а также анализ глубинного строения территории и моделей его эволюции на разных этапах развития [13].

Конфликт интересов: Авторы декларируют отсутствие явных и потенциальных конфликтов интересов, связанных с публикацией настоящей статьи.

\section{ЛИТЕРАТУРА}

1. Ненахов В. М., Стрик Ю. Н., Трегуб А. И., Холин В. М., Шабанов М. И. Минерагенические исследования территорий с двухъярусным строением (на примере Воронежского кристаллического массива). Москва: Геокарт, Геос, 2007. 284 с. 2. Чернышов Н. М., Альбеков А. Ю. Связь разновременных ареалов траппового магматизма с долгоживущими зонами региональных разломов (на примере Воронежского региона) // Связь поверхностных структур земной коры с глубинными: материалы 14-й международной конференции. Петрозаводск. 2008. Ч. 2. С. 328-331.

3. Афанасьев Н. С., Груздев В. Н., Дубянский А. И., Закутский С. Н., Морено-Пальи Л. П., Надежка Л. И., Ненахов В. М., Силкин К. Ю., Чернышов Н. М. Литосфера Воронежского кристаллического массива по геофизическим и петрофизическим данным. Воронеж: Научная книга. 2012. 330 с.

4. Чернышов Н. М., Лосицкий В. И., Молотков С. П. Структурно-тектоническое районирование Воронежского кристаллического массива (по геологическим и геофизическим данным) // Материалы юбилейной научной сессии геологического факультета ВГУ. Воронеж: изд-во Воронеж. ун-та, 1998. С. 5-7.

5. Трегуб А. И. Неотектоника территории Воронежского кристаллического массива // Труды научно-исследовательского института геологии. Воронеж: Изд-во Воронеж. гос. ун-та. Вып. 9, 2002. 220 с.

6. Шерман С. И., Днепровский Ю. И. Поля тектонических напряжений земной коры и геолого-структурные методы их изучения. Новосибирск: Наука СО, 1989. 159 с.

7. SRTM 90m DEM Digital Elevation Database [Электронный pecypc]: URL: http://srtm.csi.cgiar.org (дата обращения: 14.02.2020)

8. Раскатов Г. И. Прогнозирование тектонических структур фундамента и чехла древних платформ и форм погребенного рельефа средствами геолого-геоморфологического анализа (на примере Воронежской антеклизы). Воронеж: изд-во ВГУ, 1972. $108 \mathrm{c.}$

9. Раскатов Г. И., Лукьянов В. Ф., Старухин А. А., Сычев И. А., Холмовой Г. В., Шишов В. В. Тектоника восточной части Воронежского кристаллического массива и его осадочного чехла. Воронеж: изд-во Воронежского ун-та, 1976. 120 с.

10. Трегуб А. И., Трегуб С. А., Шевцов Д. Е. Неотектоника Шумилинско-Новохоперской зоны разломов (Воронежский кристаллический массив) // Вестник Воронежского государственного университета. Серия: Геология. 2015. № 4. С. 
171-173.

11. Трегуб А. И. Голоценовый аллювий Дона в ПавловскоМамонском прогибе // Вестник Воронежского государственного университета. Серия: Геология. 2014. № 2. С. 32-36.

12. Копп М. Л., Вержбитский В. Е., Колесниченко А. А., Тверитиновап Т. Ю., Васильев Н. Ю., Корчемагин В. А., Макарова Н. В., Мострюков А. О., Иоффе А. И. Кайнозойские напряжения востока Русской плиты, Южного и Сред- него Урала. Методические, теоретические и прикладные аспекты. Москва: ГЕОС, 2014. 88 с.

13. Минц М. В., Глазнев В. Н., Муравина О. М. Глубинное строение коры юго-востока Воронежского кристаллического массива по геофизическим данным геодинамическая эволюция в палеопротерозое и современное состояние коры // Вестник Воронежского государственного университета. Серия: Геология. 2017. №4. С. 5-23.

UDC 551.793

ISSN 1609-0691

DOI: https://doi.org/10.17308/geology.2020.1/2511

Received: 14.02 .2020

Accepted: 20.02.2020

Published online: 25.03.2020

\title{
Faults in the basement of the Eastern part of the Voronezh Crystalline Massif according to morphometric data
}

\author{
A. I. Tregub ${ }^{1 凶}$, D. E. Shevtsov ${ }^{2}$ \\ ${ }^{1}$ Voronezh State University, 1 Universitskaya pl., Voronezh 394018, Russian Federation \\ ${ }^{2}$ Institute of Geotechnics and Engineering Surveys in Construction, \\ 92 Sredne-Moskovskaya st., Voronezh 394006, Russian Federation
}

\begin{abstract}
Introduction: Faults in the basement of the Voronezh Crystalline Massif (VCM) play an important role both in the formation of the structure of the sedimentary cover and in the mineralization features of the territory. Their current activity affects the seismicity of the region, as well as the development of exogenous geological processes. Fault mapping requires an integrated approach, including geomorphological methods. However, the use of these methods have a number of limitations.

Methodology: The statistical analysis of the heights of the earth surface was performed based on a digital elevation model of the eastern part of the Voronezh Crystalline Massif. It included the definition and interpretation of the central points of the height distribution.

Results and discussion: Fault zones in the crystalline basement of the Eastern part of the Voronezh crystalline massif are selectively reflected in the morphometric parameters of the relief of the earth surface. Modern active fault zones, zones active at the neotectonic stage and fault zones, which passively appear in the digital relief model were distinguished. The thrusts and shariages that formed at the final stages of basement consolidation were not fully reflected in the morphometric indicators of the modern earth surface relief.

Conclusion: The results of the research can be used in geological mapping, engineering and geological surveys, environmental and geological studies and in seismic zoning of the territory.

Keywords: fault zones, crystalline basement, Voronezh Crystalline Massif, morphometric parameters of the relief, neotectonics, morphostructure, digital relief model.

For citation: Tregub A. I., Shevtsov D. E. Faults in the basement of the Eastern part of the Voronezh Crystalline Massif according to morphometric data. Vestnik Voronezhskogo gosudarstvennogo universiteta. Seriya: Geologiya $=$ Proceedings of Voronezh State University.

Series: Geology, 2020, No. 1, pp. 30-38. DOI: https://doi.org/10.17308/geology.2020.1/2511

Conflict of interests: The authors declare the absence of obvious and potential conflicts of interest related to the publication of this article.
\end{abstract}

The content is available under Creative Commons Attribution 4.0 License.

\footnotetext{
$\bowtie$ Alexander I. Tregub, E-mail: tregubai@yandex.ru
} 


\section{REFERENCES}

1. Nenakhov V. M., Strik Yu. N., Tregub A. I., Holin V. M., Shabanov M. I. Mineragenicheskie issledovaniya territorii s dvukh"yarusnym stroeniem (na primere Voronezhskogo kristallicheskogo massiva). [Mineralogical studies of territories with two-tiered structure (on the example of the Voronezh crystalline massif]. Moscow, GEOKART, GEOS Publ., 2007, 284 p. (in Russ.)

2. Chernyshov N. M., Al'bekov A. Yu. Connection differenttime areas of trap magmatism with long-lived zones of regional faults (on the example of the Voronezh region). Svyaz' poverkhnostnykh struktur zemnoi kory s glubinnymi: materialy 14-i mezhdunarodnoi konferentsii. [Connection of surface structure of the earth's crust with deep ones: materials of the $14^{\text {th }}$ international conference]. Petrozavodsk, 2008, pp 328-331. (in Russ.) 3. Afanasiev N. S., Gruzdev V. N., Dubyansky A. I., Zakutsky S. N., Moreno-Pal'i L. P., Nadezhka L. I., Nenakhov V. M., Silkin K. Y., Chernyshov N. M. Litosfera Voronezhskogo kristallicheskogo massiva po geofizicheskim $i$ petrofizicheskim dannym. [Lithosphere of the Voronezh crystalline massif from geophysical and petrophysical data]. Voronezh, Nauchnaya kniga Publ., 2012, 330 p. (in Russ.)

4. Chernyshov N. M., Losicky V. I., Molotkov S. P. Strukturno-tektonicheskoe raionirovanie Voronezhskogo kristallicheskogo massiva (po geologicheskim i geofizicheskim dannym). [Structural and tectonic zoning of the Voronezh crystalline massif (based on geological and geophysical data)] Materialy yubileinoi nauchnoi sessii geologicheskogo fakul'teta $V G U$. [Materials of the anniversary scientific session of the VSU faculty of Geology]. Voronezh, VSU publ., 1998, pp 5-7. (in Russ.)

5. Tregub A. I. Neotektonika territorii Voronezhskogo kristallicheskogo massiva. [Neotectonics of the territory of the Voronezh Crystalline Massif]. Trudy Nauchno-issledovatel'skogo Instituta Geologii [The work of the Research Institute of Geology]. Voronezh, VSU Publ., vol. 9, 2002, 220 p. (in Russ.)

6. Sherman S. I., Dneprovsky Y. I. Polya tektonicheskikh napryazhenii zemnoi kory $i$ geologo-strukturnye metody ikh izucheniya. [Filds of tectonic stresses of the earth's crust and geologic-structural methods for their study]. Novosibirsk, Nauka publ, Siberian branch, 1989, 159 p. (in Russ.)
7. SRTM 90m DEM Digital Elevation Database. Available at: URL: http://srtm.csi.cgiar.org (accessed 14 February 2020)

8. Raskatov G. I. Prognozirovanie tektonicheskikh struktur fundamenta $i$ chekhla drevnikh platform $i$ form pogrebennogo rel'efa sredstvami geologo-geomorfologicheskogo analiza (na primere Voronezhskoi anteklizy). [Forecasting of tectonic structure of the Foundation and cover of ancient platforms and buried relief by means of geology-geomorphological analysis (on the example of the Voronezh Anteclise)]. Voronezh, VSU publ., 1972, 108 p. (in Russ.)

9. Raskatov G. I., Luk'yanov V. F., Starukhin A. A., Sychov I. A., Holmovoy G. V., Shyshov V. V. Tektonika vostochnoi chasti Voronezhskogo kristallicheskogo massiva i ego osadochnogo chekhla. [Tectonics of the eastern part of the Voronezh Crystalline Massif and its sedimentary cover]. Voronezh, VSU publ., 1976, 120 p. (in Russ.)

10. Tregub A. I., Tregub C. A., Shevtsov D. E. Neotectonics of the Shumilinsko-Novokhopersk fault zone (Voronezh Crystalline Massif). Vestnik Voronezhskogo gosudarstvennogo universiteta. Seriya: Geologiya $=$ Proceedings of Voronezh State University. Series: Geology, 2015, no. 4. pp 171-173. (in Russ.)

11. Tregub A. I. Holocene alluvium of the Don in the PavlovskMamon trough. Vestnik Voronezhskogo gosudarstvennogo universiteta. Seriya: Geologiya $=$ Proceedings of Voronezh State University. Series: Geology, 2014, no. 2, pp 32-36. (in Russ.) 12. Kopp M. L., Verzhbitsky V. E., Kolesnichenko A. A., Tveritinova T. Yu., Vasil'ev N. Yu., Korchemagin V. A., Makarova N. V., Mostryukov A. O., Ioffe A. I. Kainozoiskie napryazheniya vostoka Russkoi plity, Yuzhnogo i Srednego Urala. Metodicheskie, teoreticheskie $i$ prikladnye aspekty. [Cenozoic stress field in the East of the Russian plate, Southern and Midle Urals. Methodical, theoretical and applied aspects]. Moscow, GEOS publ., 2014, 88 p. (in Russ.)

13. Mints M. V., Glaznev V. N., Muravina O. M. Deep crustal structure in South-East of Voronezh crystalline massif on geophysical data: geodynamic evolution of Paleoproterozoic and the current state of crust. Vestnik Voronezhskogo gosudarstvennogo universiteta. Seriya: Geologiya $=$ Proceedings of Voronezh State University. Series: Geology, 2017, no. 4, pp 523. (in Russ.)
Трегуб Александр Иванович - д.г.-м.н., профессор кафедры общей геологии и геодинамики, Воронежский государственный университет, Воронеж, Российская Федерация; Еmail: tregubai@yandex.ru;

ORCID http://orcid.org/0000-0002-8653-1165

Шевцов Дмитрий Евгеньевич - ведущий специалист, Институт геотехники и инженерных изысканий в строительстве, Воронеж, Российская Федерация; E-mail: dmitri@ mail.ru; ORCID http: //orcid.org/0000-0003-3237-5539

Авторы прочитали и одобрили окончательный вариант рукописи.
Aleksandr I. Tregub - PhD, Dr. habil. in Geol.-Min., Professor, Department of General Geology and Geodynamics, Voronezh State University, Voronezh, Russian Federation; E-mail: tregubai@yandex.ru; ORCID http://orcid.org/0000-0002-8653-1165

Dmitrii E. Shevtsov - leading specialist, Institute of geotechnics and engineering surveys in construction, Voronezh, Russian Federation; E-mail: dmitri@mail.ru; ORCID http: //orcid.org/0000-0003-3237-5539

All authors have read and approved the final manuscript. 